\title{
STATUS GIZI MENURUT TINGGI BADAN PER UMUR PADA BALITA
}

\author{
Height-for-Age Nutritional Status among Under 5 Years
}

\author{
Kadar Ramadhan \\ Poltekkes Kemenkes Palu \\ (Email korespondensi: kadarlaure@gmail.com)
}

\begin{abstract}
ABSTRAK
Stunting menjadi masalah kesehatan yang penanganannya membutuhkan kerjasama lintas sektor dan masuk dalam prioritas nasional. Kegiatan konvergensi pencegahan stunting membutuhkan data yang valid agar intervensi spesifik dan sensitif yang telah direncanakan oleh pemerintah tepat sasaran. Penelitian ini bertujuan untuk mengetahui prevalensi stunting anak $0-5$ tahun. Penelitian ini merupakan penelitian observasional dengan pendekatan cross-sectional melibatkan 425 anak di Kecamatan Lore Selatan Kabupaten Poso Propinsi Sulawesi Tengah. Data penelitian diperoleh dari Puskesmas Gintu yang berasal dari pengukuran antropometri posyandu bulan Agustus 2018. Hasil penelitian menunjukan prevalensi stunting sebesar 34,8\%, Desa Pada dengan prevalensi tertinggi 42,1\% dan Desa Bewa terendah dengan $18,6 \%$. Penelitian ini menyarankan agar kegiatan konvergensi stunting harus segera dilaksanakan dengan memanfaatkan sumber daya yang ada di desa.
\end{abstract}

Kata Kunci: Status Gizi; Tinggi Badan per Umur

\begin{abstract}
Stunting becomes one of the national health priority issue and it demands cross sectoral collaboration. Data validity is necessary in stunting preventive convergence to achieve government's sensitive and specific interventions. This study aims to determine the prevalence of stunting of children $0-5$ years. A community-based cross-sectional study was conducted among 425 children aged between 0 and 59 months in the South Lore Subdistrict. Data was accessed from posyandu anthropometrical measurement in Puskesmas Gintu August 2018. The data analysis was done by WHO Antro software for anthropometric calculation. The results showed the prevalence of stunting was $34.8 \%$, Pada Village is the highest with $42,1 \%$ and Bewa Village is the lowest with $18,6 \%$. This research suggest the stunting convergence activities should be implemented using local resource in the village level.
\end{abstract}

Keyword: Height-for-Age; Nutrition Status

\section{PENDAHULUAN}

Stunting mencerminkan kekurangan gizi kronis selama periode pertumbuhan dan perkembangan paling kritis pada awal kehidupan yang disebabkan oleh malnutrisi kronik $^{(1)(2)}$. Pertumbuhan anak adalah salah satu indikator kesehatan masyarakat dalam memantau status gizi dan kesehatan suatu populasi. Stunting adalah keadaan pertumbuhan tinggi badan tidak sesuai umur, berada dibawah 2 Standar Deviasi (SD) median tinggi badan populasi anak ${ }^{(3)(4)}$. Stunting di seluruh dunia mempengaruhi sekitar 162 juta anak balita. Indonesia termasuk dalam 17 negara yang memiliki tiga masalah gizi pada anak balita: stunting, wasting, dan kelebihan berat badan ${ }^{(5)}$.

Hasil Riset Kesehatan Dasar (Riskesdas)
2018 menunjukkan bahwa bayi usia di bawah lima tahun (balita) yang menderita stunting mencapai $30,8 \%$. Artinya, sebanyak 7 juta balita di Indonesia saat ini yang merupakan generasi bangsa terancam kurang memiliki daya saing pada kehidupannya ke depan. Penurunan angka stunting di Indonesia selama 10 tahun terakhir belum menunjukkan adanya perubahan yang berarti $^{(6)}$.

Angka stunting di Sulawesi tengah mengalami penurunan. Berdasarkan data Riskesdas 2013 prevalensi stunting 41\% turun menjadi $32,3 \%$ tahun $2018^{(7)(8)}$. Diantara tahun itu diadakan pula Pemantauan Status Gizi (PSG) dimana tahun 2016 prevalensi stunting sebesar $32 \%$ dan tahun 2017 naik menjadi $36,1 \%{ }^{(9)(10)}$. Untuk prevalensi stunting baduta terdapat penurunan sebesar $6,2 \%$ dalam kurun waktu 9 
tahun dari tahun 2007 ke tahun 2016, atau ratarata mengalami penurunan $0,6 \%$ pertahun $^{(11)}$.

Di Kabupaten Poso, prevalensi stunting tahun 2013 sebesar $39,4 \%$ dan turun menjadi $26,2 \%$ tahun 2018. Penurunan yang cukup banyak ini menempatkan Poso sebagai Kabupaten posisi ke-3 terendah stunting setelah Kota Palu dan Kab. Tojo Una-Una ${ }^{(7)(8)}$.

Walaupun prevalensi stunting cenderung turun, namun angka tersebut masih diatas standar yang ditetapkan oleh WHO yaitu dibawah $20 \%{ }^{(12)(13)}$. Pemerintah melalui Kementerian Desa, Pembangunan Daerah Tertinggal dan Transmigrasi lewat Permendes No. 16 Tahun 2018 tentang Prioritas Penggunaan dana Desa 2019 memasukkan stunting sebagai program prioritas untuk segera diselesaikan melalui kegiatan konvergensi pencegahan stunting. Dengan mengalokasikan dana desa untuk melaksakan kegiatan konvergensi dengan harapan bisa mencegah dan menurunkan prevalensi stunting ${ }^{(14)}$.

Kecamatan Lore Selatan merupakan salah satu kecamatan yang berada di Kabupaten Poso yang terletak di Lembah Bada. Balita di sana sangat berpotensi untuk mengalami stunting karena lokasinya yang cukup terpencil dan jauh dari pesisir. Tujuan penelitian ini adalah untuk mengetahui gambaran status gizi balita tinggi badan per umur di Kecamatan Lore Selatan sehingga dapat dijadikan baseline data untuk melaksanakan kegiatan konvergensi pencegahan stunting.

\section{METODE PENELITIAN}

Penelitian ini merupakan penelitian deskriptif, yaitu menggambarkan besaran masalah status gizi yang terjadi di Kecamatan Lore Selatan Wilayah Kerja Puskesmas Gintu. Penelitian dilaksanakan di Kecamatan Lore Selatan Wilayah Kerja Puskesmas Gintu. Populasi dalam penelitian ini adalah seluruh anak berumur $0-60$ bulan. Berdasarkan data dari puskesmas berjumlah 425 orang. Sampel dari penelitian ini adalah seluruh populasi anak berumur $0-60$ bulan. Penelitian ini adalah menganalisis data sekunder. Data sekunder ini adalah laporan rutin puskesmas ke Dinas Kesehatan Kabupaten Poso. Data diperoleh dari Dinas Kesehatan Kabupaten Poso pada pemegang program gizi. Hasil analisis disajikan dalam bentuk tabel dan grafik

\section{HASIL DAN PEMBAHASAN}

A. Hasil

Tabel 1 Status Gizi berdasarkan Tinggi Badan per Umur (TB/U) di Kecamatan Lore Selatan Tahun 2018

\begin{tabular}{|c|c|c|c|c|c|c|c|c|c|c|}
\hline \multirow{3}{*}{ Desa } & \multicolumn{10}{|c|}{ Status Gizi TB/U } \\
\hline & \multicolumn{2}{|c|}{ Sangat Pendek } & \multicolumn{2}{|c|}{ Pendek } & \multicolumn{2}{|c|}{ Normal } & \multicolumn{2}{|c|}{ Tinggi } & \multicolumn{2}{|c|}{ total } \\
\hline & $\mathrm{n}$ & $\%$ & $\mathrm{n}$ & $\%$ & $\mathrm{n}$ & $\%$ & $\mathrm{n}$ & $\%$ & $\mathrm{n}$ & $\%$ \\
\hline Bomba & 5 & 10,9 & 9 & 19,6 & 32 & 69,6 & 0 & 0,0 & 46 & 100,0 \\
\hline Pada & 4 & 10,5 & 12 & 31,6 & 22 & 57,9 & 0 & 0,0 & 38 & 100,0 \\
\hline Bewa & 3 & 5,6 & 7 & 13,0 & 44 & 81,5 & 0 & 0,0 & 54 & 100,0 \\
\hline Gintu & 14 & 16,3 & 14 & 16,3 & 58 & 67,4 & 0 & 0,0 & 86 & 100,0 \\
\hline Runde & 10 & 18,2 & 10 & 18,2 & 34 & 61,8 & 1 & 1,8 & 55 & 100,0 \\
\hline Badangkaia & 11 & 16,2 & 17 & 25,0 & 40 & 58,8 & 0 & 0,0 & 68 & 100,0 \\
\hline Bakekau & 4 & 11,1 & 10 & 27,8 & 22 & 61,1 & 0 & 0,0 & 36 & 100,0 \\
\hline Bulili & 5 & 11,9 & 13 & 31,0 & 24 & 57,1 & 0 & 0,0 & 42 & 100,0 \\
\hline Lore Selatan & 56 & 13,2 & 92 & 21,6 & 276 & 64,9 & 1 & 0,2 & 425 & 100,0 \\
\hline
\end{tabular}

Tabel 2: Status Gizi berdasarkan Tinggi Badan per Umur (TB/U) menurut umur dan jenis kelamin di Kecamatan Lore Selatan Tahun 2018

\begin{tabular}{crrrrrr}
\hline \multirow{2}{*}{ Variabel } & \multicolumn{6}{c}{ Status gizi } \\
\cline { 2 - 7 } & \multicolumn{2}{c}{ Stunting } & \multicolumn{2}{c}{ Tidak stunting } & \multicolumn{2}{c}{ Jumlah } \\
\hline Umur & $\mathrm{n}(148)$ & $\%(34,8)$ & $\mathrm{n}(277)$ & $\%(65,2)$ & $\mathrm{n}(425)$ & $\%$ \\
\hline $0-23$ bulan & 47 & 26,9 & 128 & 73,1 & 175 & 100,0 \\
$24-59$ bulan & 101 & 40,4 & 149 & 59,6 & 250 & 100,0 \\
\hline Jenis Kelamin & & & & & & \\
\hline Laki-laki & 76 & 36,9 & 130 & 63,1 & 206 & 100,0 \\
Perempuan & 72 & 32,9 & 147 & 67,1 & 219 & 100,0 \\
\hline
\end{tabular}




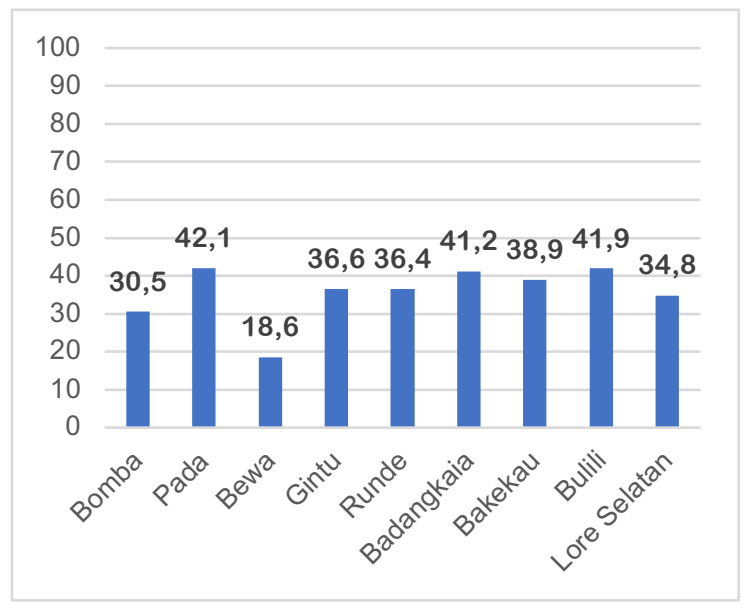

Gambar 1: Prevalensi Stunting (sangat pendek+pendek) di Kecamatan Lore Selatan Tahun 2018

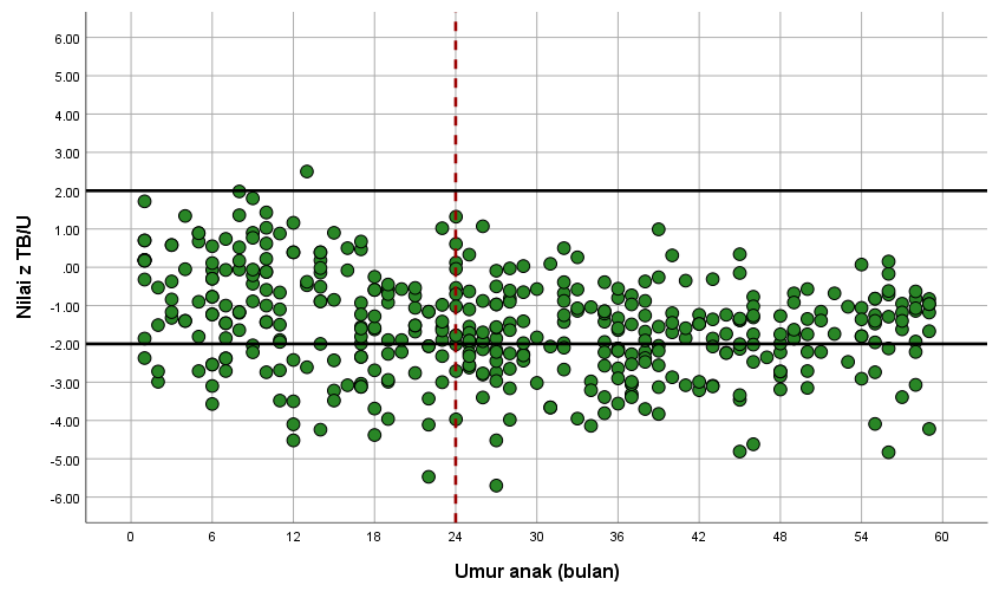

Gambar 2: Sebaran Nilai z TB/U Balita berdasarkan Umur di Kecamatan Lore Selatan Tahun 2018

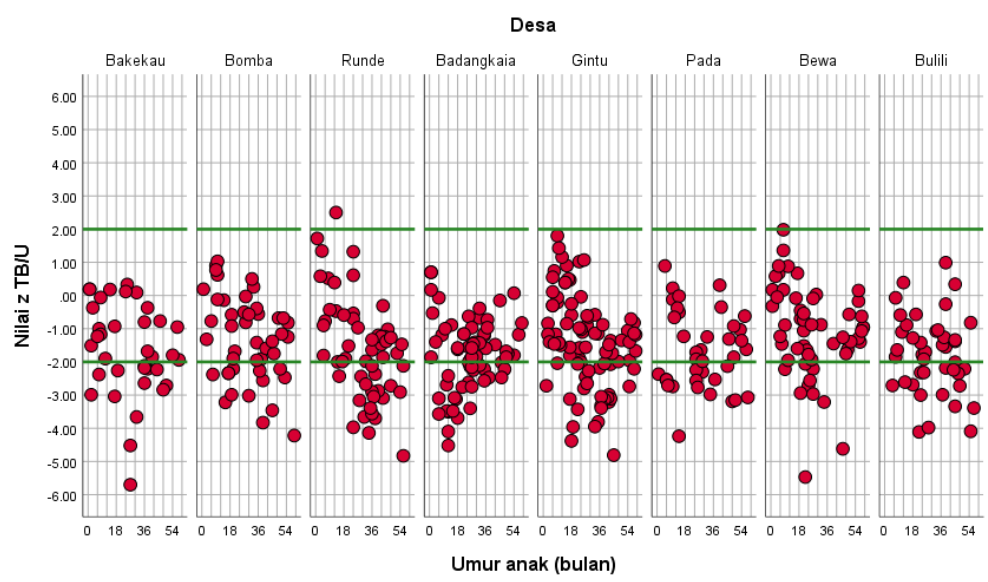

Gambar 3: Sebaran Nilai z TB/U Balita berdasarkan Umur per Desa di Kecamatan Lore Selatan Tahun 2018 


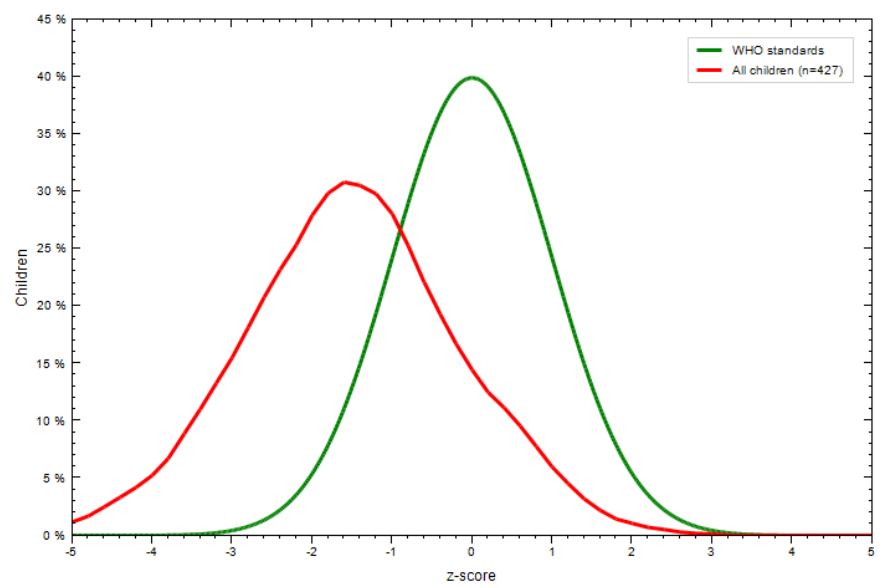

Gambar 4: Grafik Penyimpangan Status Gizi TB/U terhadap Standar Normal Pertumbuhan di Kecamatan Lore Selatan Tahun 2018

B. Pembahasan

Prevalensi stunting di Kecamatan Lore Selatan masuk pada kategori tinggi. Pada tabel 1 menunjukan prevalensi sangat sangat pendek sebesar $13,2 \%$ dan pendek $21,6 \%$. Jika diakumulasikan menjadi $34,8 \%$ (gambar 1). Dari 8 Desa yang terdapat di Kecamatan Lore Selatan, hanya 1 desa yang prevalensi stuntingnya rendah kurang dari $20 \%$ yaitu Desa Bewa $(18,6 \%)$, sedangkan 3 desa tertinggi yaitu Pada (42,1\%), Bulili $(41,9 \%)$, dan Badangkaia $(41,2)$. Di 3 desa tersebut, dari 10 anak balita, 4 anak mengalami stunting.

Gambar 2 menunjukan visualisasi sebaran nilai z TB/U balita. Dari gambar nampak banyak titik-titik yang berada di bawah -2SD bahkan sampai di bawah -3SD. Ini menandakan masih banyak anak yang pertumbuhan tinggi badannya bermasalah (sangat pendek+pendek). Pada gambar 3 merupakan visualisasi sebaran nilai z TB/U berdasarkan desa. Dilihat dari grafik (gambar 4) penyimpangan status gizi $\mathrm{TB} / \mathrm{U}$ (garis merah) terhadap standar normal pertumbuhan WHO (garis warna hijau) nampak bahwa terjadi penyimpangan ke kiri dari standar normal. Pekerjaan rumah kita adalah berusaha untuk "menarik masuk" garis merah ke dalam garis hijau.

Dilihat dari umur pada tabel 2, angka stunting cenderung lebih tinggi pada anak 24 - 59 bulan sebesar 40,4\% dibandingkan anak 0 - 23 bulan (baduta) sebesar 26,9\%. Peningkatanya hampir 2 kali lipat. Olehnya itu, intervensi 1000 Hari Pertama Kehidupan (HPK) harus segera dilakukan agar bisa ditekan ketika anak masih dalam periode emas (gold period). Telah banyak penelitian yang membuktikan efektivitas 1000 HPK dalam perbaikan gizi anak untuk mencegah stunting $^{(15)(16) .}$ Selain itu perbaikan sanitasi melalui program sanitasi total berbasis masyarakat (STBM) yang membudayakan perilaku hidup bersih dan sehat, mencegah penyebaran penyakit berbasis lingkungan harus terus digalakkan ${ }^{(17)}$.

Perhatian pemerintah untuk menurunkan prevalensi stunting sangat baik. Wujud nyata dari upaya pencegahan stunting secara terkonvergensi adalah Kementerian Desa, Pembangunan Daerah Tertinggal, dan Transmigrasi, memfasilitasi terbentuknya Kader Pembangunan Manusia (KPM). Tenaga pendamping masyarakat Desa bersama-sama dengan KPM memfasilitasi Pemerintahan Desa dan masyarakat Desa mencegah stunting di Desa ${ }^{(18)}$. Intervensi pencegahan stunting harus melalui konvergensi program yang melibatkan pelaku lintas sektor di tingkat Pusat, Daerah, dan Desa. Untuk itu maka dibutuhkan kesiapan dan kapasitas yang memadai oleh masyarakat dan pemerintah desa selaku pelaku pembangunan yang bersentuhan langsung dengan sasaran, khususnya kepada rumah tanggga 1.000 Hari Pertama Kehidupan (HPK) ${ }^{(19)}$.

Kader Pembangunan Manusia (KPM) adalah warga masyarakat Desa yang dipilih melalui musyawarah Desa untuk bekerja membantu pemerintah Desa dalam memfasilitasi masyarakat Desa dalam merencanakan, melaksanakan dan 
mengawasi pembangunan sumberdaya manusia di Desa. Tugas KPM adalah: a). Mensosialisasikan kebijakan konvergensi pencegahan stunting di Desa kepada masyarakat di Desa, termasuk memperkenalkan tikar pertumbuhan untuk pengukuran panjang/tinggi badan baduta sebagai alat deteksi dini stunting; b) Mendata sasaran rumah tangga $1.000 \mathrm{HPK} ; \mathrm{c}$ ) Memantau layanan pencegahan stunting terhadap sasaran rumah tangga 1.000 HPK untuk memastikan setiap sasaran pencegahan stunting mendapatkan layanan yang berkualitas; d) Memfasilitasi dan mengadvokasi peningkatan belanja APBDes utamanya yang bersumber dari Dana Desa, untuk digunakan membiayai kegiatan pencegahan stunting berupa layanan intervensi gizi spesifik dan sensitif; e) Memfasilitasi suami ibu hamil dan bapak dari anak usia 0-23 bulan untuk mengikuti kegiatan konseling gizi serta kesehatan ibu dan anak. f) Memfasilitasi masyarakat Desa untuk berpartisipasi aktif dalam perencanaan, pelaksanaan dan pengawasan program/ kegiatan pembangunan Desa untuk pemenuhan layanan gizi spesifik dan sensitif; g) Melaksanakan koordinasi dan/atau kerjasama dengan para pihak yang berperan serta dalam pelayanan pencegahan stunting, seperti bidan Desa, petugas puskesmas (ahli gizi, sanitarian), guru PAUD dan/atau perangkat Desa ${ }^{(20)(19)}$.

Program pemerintah pusat sudah sangat baik. Yang dinantikan sekarang adalah kemampuan dari pemerintah kabupaten untuk menjalankan program tersebut. Institusi pendidikan bisa mengambil peran dalam program ini, misalnya melakukan pendampingan terhadap KPM. Tugas KPM sungguh sangat berat, jadi dibutuhkan orang yang tepat untuk menjadi kader ini.

\section{KESIMPULAN DAN SARAN}

Prevalensi stunting di kecamatan Lore Selatan $34,8 \%$, masih masuk kategori tinggi. Penelitian ini menyarankan agar kegiatan konvergensi harus segera dilakukan. Olehnya itu Pemerintah desa harus berkomitmen untuk menganggarkan pada dana desa untuk pencegahan dan penanggulangan stunting.

\section{UCAPAN TERIMA KASIH}

Ucapan terima kasih disampaikan kepada Camat Lore Selatan dan Kepala Puskesmas Gintu yang telah banyak membantu dalam pelaksanaan penelitian ini.

\section{DAFTAR PUSTAKA}

1. Abeway S, Gebremichael B, Murugan R, Assefa M, Adinew YM. Stunting and Its Determinants among Children Aged 6-59 Months in Northern Ethiopia: A Cross-Sectional Study. J Nutr Metab [Internet]. 2018 Jun 25 [cited 2019 Nov 27];2018:1-8. Available from: https://www.hindawi.com/journals/jnme/2018/1 078480/

2. Imelda, Rahman N, Nur R. Faktor Risiko Kejadian Stunting Pada Anak Umur 2-5 Tahun Di Puskesmas Biromaru. Ghidza J Gizi Dan Kesehat [Internet]. 2018;2(1):39-43. Available from: http://jurnal.untad.ac.id/jurnal/index.php/ghidza/ article/view/10369/pdf

3. Atsu BK, Guure C, Laar AK. Determinants of Overweight with Concurrent Stunting among Ghanaian Children. BMC Pediatr [Internet]. 2017 Dec [cited 2019 Nov 27];17(1):177. Available from:

http://bmcpediatr.biomedcentral.com/articles/10. 1186/s12887-017-0928-3

4. Agustia R, Rahman N, Hermiyanty H. Faktor Risiko Kejadian Stunting Pada Balita Usia 12-59 Bulan Di Wilayah Tambang Poboya, Kota Palu. Ghidza J Gizi Dan Kesehat [Internet]. 2018;2(2):59-62. Available from: http://jurnal.untad.ac.id/jurnal/index.php/ghidza/ article/view/11258/pdf

5. Rahmawati VE, Pamungkasari EP, Murti B. Determinants of Stunting and Child Development in Jombang District. J Matern Child Health [Internet]. 2018 [cited 2019 Nov 27];03(01):6880. Available from: http://thejmch.com/index.php?journal=thejmch\& page $=$ article \&op $=$ view\&path $\% 5 \mathrm{~B} \% 5 \mathrm{D}=81 \&$ pat $\mathrm{h} \% 5 \mathrm{~B} \% 5 \mathrm{D}=91$

6. Kementerian Kesehatan R.I. Laporan Nasional Riskesdas 2018. Jakarta: Badan Penelitian dan Pengembangan Kesehatan; 2018.

7. Kementerian Kesehatan R.I. Laporan Nasional Riset Kesehatan Dasar (RISKESDAS) 2013). Jakarta: Badan Penelitian dan Pengembangan Kesehatan, Kementerian Kesehatan R.I; 2013.

8. Kementerian Kesehatan R.I. Laporan Nasional Riset Kesehatan Dasar 2018. Jakarta: Badan Penelitian dan Pengembangan Kesehatan, Kementerian Kesehatan R.I; 2018.

9. Kementerian Kesehatan R.I. Buku Saku Pemantauan Status Gizi Provinsi Sulawesi Tengah tahun 2016. Jakarta: Direktorat Gizi 
Masyarakat Direktorat Jenderal Kesehatan Masyarakat Kementerian Kesehatan; 2017.

10. Kementerian Kesehatan R.I. Buku Saku Pemantauan Status Gizi Provinsi Sulawesi Tengah Tahun 2017. Jakarta: Direktorat Gizi Masyarakat Direktorat Jenderal Kesehatan Masyarakat Kementerian Kesehatan; 2018.

11. Nasrul, Maudu R, Hafid F. Trend and Prevalence of Stunting In Children Under Two Years From 2007-2016 In Central Sulawesi. Prev J Kesehat Masy [Internet]. 2017;8(2):73-8. Available from: http://jurnal.untad.ac.id/jurnal/index.php/Prevent if/article/view/9402/7491

12. de Onis M, Borghi E, Arimond M, Webb P, Croft T, Saha K, et al. Prevalence Thresholds for Wasting, Overweight and Stunting in Children Under 5 Years. Public Health Nutr [Internet]. 2019 Jan [cited 2019 Nov 29];22(1):175-9. Available from: https://www.cambridge.org/core/product/identifi er/S1368980018002434/type/journal_article

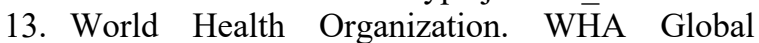
Nutrition Targets 2025: Stunting Policy Brief [Internet]. Geneva, Switzerland: World Health Organization; 2018. Available from: https://www.who.int/nutrition/topics/globaltarget s stunting policybrief.pdf

14. Kementerian Desa, Pembangunan Daerah Tertinggal dan Transmigrasi. Peraturan Menteri Desa Pembangunan Daerah Terpencil dan Transmigrasi No.16 tahun 2018 tentang Prioritas Penggunaan Dana Desa Tahun 2019. Kementerian Desa, Pembangunan Daerah Tertinggal dan Transmigrasi; 2019.

15. Nefy N, Lipoeto NI, Edison E. Implementation of The First 1000 Days of Life Movement in Pasaman Regancy 2017. Media Gizi Indones
[Internet]. 2019 Jul 1 [cited 2019 Nov 29];14(2):186. Available from: https://ejournal.unair.ac.id/MGI/article/view/11140

16. Sugihantono A. Hari Gizi Nasional Ke-58: Cegah Stunting, Bersama Keluarga Kita Jaga 1000 Hari Pertama Kehidupan [Internet]. Kementerian Kesehatan Republik Indonesia. 2018. Available from:

https://www.depkes.go.id/article/print/18012600 001/hari-gizi-nasional-ke-58-cegah-stuntingbersama-keluarga-kita-jaga-1000-hari-pertamakehidupan-.html

17. Hafid F, Djabu U, Udin, Nasrul. Efek Program SBABS Terhadap Pencegahan Stunting Anak Baduta di Kabupaten Banggai dan Sigi. Indones J Hum Nutr [Internet]. 2017 Dec 29 [cited 2019 Dec 25];4(2):79-87. Available from: http://ijhn.ub.ac.id/index.php/ijhn/article/view/2 23

18. Kementerian Desa, Pembangunan Daerah Tertinggal dan Transmigrasi. Panduan Fasilitasi Konvergensi Pencegahan Stunting di Desa. Jakarta: Direktorat Jenderal Pembangunan dan Pemberdayaan Masyarakat Desa; 2018.

19. Kementerian Desa, Pembangunan Daerah Tertinggal dan Transmigrasi. Pedoman Umum Kader Pembangunan Manusia. Jakarta: Direktorat Jenderal Pembangunan dan Pemberdayaan Masyarakat Desa; 2018.

20. Kementerian Desa, Pembangunan Daerah Tertinggal dan Transmigrasi, Human Development Worker. Buku Saku Kader Pembangunan Manusia (KPM): Memastikan Konvergensi Penanganan Stunting Desa. Jakarta: Kementerian Desa, Pembangunan Daerah Tertinggal dan Transmigrasi; 2018. 